\title{
The Role of History in the Teaching of Anthropology
}

\author{
David Shankland \\ Royal Anthropological Institute
}

Recently, at the RAI we have been encouraging research and discussion into the history of anthropology. This has been yielding most interesting insights, particularly as to the changing role of the RAI over the years. At one of our seminars, however, I was struck by a particular remark made to me by a distinguished retired professor, when he said to me words to the effect; 'Please don't be surprised if my colleagues still in post are not here to speak - the history of the discipline is something that one only undertakes after one is retired. Whilst one is still teaching, there is little time to do anything other than be preoccupied with one's own material'.

We can all think of exceptions to this rule, of course. However, in general terms he was quite correct in implying that the history of anthropology, so far as I know, does not form a central part of the curriculum of any single honours degree in anthropology in the country. I regard this as being a great mistake. I would go further, and say that a major course on the history of anthropology should form a core part of our teaching.

Here, I should immediately make a clarification. I am aware that many programmes in anthropology have an introduction to the subject that incorporates remarks on the discipline's past, usually within the framework of changing theoretical parameters. However, this is not history per se, rather reflections written from the point of view of the present. Let me give an example of what I mean, albeit over-simplified. I have been equally struck by the number of undergraduate essays I have read recently which summarise the history of anthropology roughly as follows: at some time in the nineteenth century there were some so-and-sos who though they interested themselves in anthropology, did so from the perspective of evolutionism, which we now realise is quite wrong. They were followed by a group of equally misguided anthropologists who though they at least conducted fieldwork believed in something called structural-functionalism that has been shown to be quite wrong. They were followed by some equally misguided researchers who believed in something called 'structuralism', which though a step in the right direction was equally quite wrong. However, from France (the original location of structuralism) at last came post-modernism, which gave rise to relativism and the happy realisation that we are in a post-positivist world where all ideas are equal.

I have, of course, over-simplified. However, as an overall presentation of the history of anthropology it is congruent with the training I received as an under-graduate in the 1980s. It is also congruent with the admittedly far more nuanced presentation that is given by Kuper, in his rightly famous and admirable Anthropology and Anthropologists (1973; 1983; 1991; 2015). I have used this text myself for many years in teaching, and have learnt a great deal from it. The problem is that can no longer bring myself to believe in it, however much I admire it as a piece of work (Shankland 2016). Quite the reverse, I think that it could become misleading, because it potentially supports a $W$ eltanschaunng that justifies and perpetuates divisions within anthropology which are arguably unnecessary.

I should explain in a little more detail what I mean by this. As everyone who reads this is I am sure aware, anthropology only split into its respective sub-divisions in a distinct way between the two wars, a process which continued after the Second World War. The way that this actually happened is complex in detail, and may be linked partially at least to the gradual emergence of two contrasting methodologies: that of archaeology which employed stratigraphy and large dig teams in order to excavate on particular sites, and that of social 
anthropology, which increasingly moved toward single-practitioner fieldwork (Shankland 2012). This created an inner tension which I am convinced would have resulted in some fission within anthropology irrespective of the personalities involved.

This tension however was greatly exacerbated by the particular way that social anthropology coalesced as an independent discipline. It is historically perfectly accurate to say that departments of anthropology were opened up by those by and large who had attended the Malinowski seminar at the London School of Economics. This helped to create a quite extra-ordinary inner coherence that even today is not totally lost. It is remarkable, even almost a century later, how many colleagues can trace their academic lineage back to those who attended that seminar, and hence back to Malinowski himself. I myself have been equally guilty of falling into this quasispiritual allusion, pointing out in lectures that my supervisor was trained by Stirling and Firth, both of whom go back to Malinowski, Stirling via Evans-Pritchard and Firth directly. It is precisely this that led Gellner (1995) to suggest that there is a Biblical divide in the history of anthropology: with the modern history being traceable back to its prophetic founding figure, and the period before him being seemingly confused, but with the occasional well-known name standing out.

Nevertheless, however worthy, the creation of that coherence led to an oversimplification of the complex intellectual roots of the discipline and its historical development. To put it in blunter terms: that very social cohesion resulted in an historical understanding that helped to create group consciousness. In doing so, as is so often the case when ideologies are so firmly embedded into a particular context, much was forgotten, and much was stripped out in the making.

Here, I should emphasise immediately that I do not intend this as a criticism. To open up specific sub-paths within a wider academic inquiry can be immensely creative, as Kuhn (1962) so long ago underlined. I am trained as a social anthropologist, and I am proud to be one. Indeed, I hope that I shall always continue to conduct research along the lines that it proposes more than thirty years after my first steps in Morocco, where I ventured on my Masters fieldwork whilst still an undergraduate at Edinburgh.

But at the same time, we can recognise the very great costs that such an intellectual over-simplification may give rise to. One of these is disciplinarily narrowness: social anthropology clearly excluded archaeology. Indeed, the well-known acerbic comments of Leach (1977) at one early attempt to bring the two disciplines together again reinforce just how far this separation had gone at its height.

The study of diffusion also was excluded. I cannot be the only social anthropologist who recalls the way that Sir Grafton Elliot Smith, its leading proponent, was held up for decades as a kind of comic buffoon, the hopeless foil at UCL as Malinowski showed the way at the LSE. Yet, the truth is far more complicated than this. Far from being such a hopeless case, a closer look at his biography (Crook: 2012) shows that he was a courageous and principled man: he was the only member of the RAI who wished in 1934 publicly to condemn Nazi racism, and did so in spite of opposition from his anthropological colleagues.

\section{Elliot Smith and Race}

As this is not a fact which one finds in the current texts, it might be useful to describe this in a little detail as an example. The occasion was the first conference of the International Congress of Anthropological and Ethnographical Sciences, which took place at UCL (Congrés 1934). Sir John Myres, who had worked for more than a decade to realise the conference as a true international forum, was anxious to avoid controversy with regard to the German delegation, which had as its official head Eugen Fischer. Fischer, a well-known physical anthropologist, had become the Director of the Kaiser-Wilhelm Institut fuer Anthropologie, Ehrblehre and Rassenhygiene in Berlin, and eventually the University Rector. Though Fischer was never formally implicated as a war criminal, it is clear that he was deeply associated with Nazi racial policies, and may be regarded as a leading figure in bringing about anthropology's concatenation with the National Socialist regime (Glass 1981, Weingart 1989, Gingrich 2005, Weiss 2006).

Already at that date, the rapid imposition of anti-Semitic racial politics by the Nazis was becoming clear in Britain, partly through Jewish intellectuals, such as Zollschan (1877-1948). Zollschan was an Austrian physician who despairing at the developments in Germany, travelled Europe in the early 1930s in the hope of creating 
academic interest in the subject of race, and in doing so highlight its distortions at the hands of the Nazis (Zollschan 1943). Convinced that this should be treated at an international level, he suggested that it be studied through the Institute for Intellectual Cooperation of the League of Nations.

He gained some support, particularly from the Czech Republic, the Holy See, and potentially also the French. When he came to the London he was less well received. Though encouraged by Seligman, he was not taken up by the RAI more widely in this effort, in part because they wished to consider the question of race scientifically; that is without bringing politics into the discussion. To his immense frustration, his efforts therefore either to bring about a special conference, or to obtain encouragement for the League of Nations to become involved fell on deaf ears.

The 1934 congress, so long in the planning could have been one possible locus for such debates. There were sections on Biological Anthropology, and there was widespread international participation, thanks to Myres' indefatigable efforts. However, even here Zollschan was not encouraged to take part, and was allowed only to leave some of his pamphlets (Zollschan 1934) at a display table. At the respective section meetings, however, Elliot Smith helped to facilitate a co-ordinated move to pass the following motion:

"In view of the fallacious use of the term Aryan, increasingly prevalent at the present day, with the implied association with inherent mental aptitude and cultural achievements, this section urges the desirability for organized research in various countries, and considers that this research could best be carried out in connection with or under the direction of the International Institute for Intellectual Co-operation". $2^{\text {nd }}$ August 1934. (RAI archives: 62/188/13)

Myres, however, who as the instigator and organiser of the Congress was in charge of its secretariat, did not approve at all of this manoeuvre. He supressed the motion, so that it never reached the full congress forum. In spite of this, Elliot Smith ensured that he used the opportunity provided by his being the Chair of Section Aa, 'Anatomy and Physical Anthropology' to make a strong statement, one that must have been all more striking as Eugen Fischer was one of its Vice-Chairmen (and therefore presumably present in the room), arguing that there was no connection between culture and race, partly because it was abundantly clear that 'civilisation' could spread from one location to another. He was also quite explicit in his criticism of the use of the word 'Aryan';

Those who insist upon the moral and intellectual qualities of the so-called "Aryans" and talk about primitive Aryan culture should be reminded that it is more than doubtful whether the Aryans did invent a primitive culture in any other way than by borrowing from Babylonia... and was in fact due to Semitic influences...

This further illustrates the fallacy of attributing mental aptitudes to different races and the neglect of the ever-significant influence of the contacts of different peoples...

...it becomes an increasing matter of surprise that the facts of anthropology should be so flagrantly misused at the present time by applying the word "Aryan" as equivalent to non-Jewish....we in this section are surely within our rights in criticizing fallacies that come into flagrant conflict with the generally recognized teaching of anthropological science. For though we are essentially concerned with the biological problems of mankind, it is important to insist upon the intimate connection which exists between all the varied manifestations of the human spirit. (Elliot Smith 1934; 65-68).

I do not wish to over-simplify in turn: Myres had no sympathy with the German position, it was rather that he wanted to maintain good relations with Germany academics, partly in the hope that talking with them in a neutral intellectual way would yield a better result than condemning them, partly because he wanted their presence in the international arena to counter-balance the influence of the French, who were his chief antagonists (Myres 1931). He was also genuinely unsure as to the right way forward intellectually with regard to discussions about race, hoping that a committee on 'Race' formed by the RAI would be able to reach some kind of resolution (Barkan 1992).

However, that same over-caution without a doubt contributed to the RAI failing, at least at that point in time, to develop the intellectual tools to tackle a vital issue (Glass 1981, Banton 2015). Elliot Smith's refusal to yield was, 
to my mind, a courageous and necessary stand, one for which he has never received any recognition, even though it forms part of the official conference record.

Further, to return to the central intellectual question, the dismissal of Elliot Smith's theoretical position meant that the study of diffusion passed from the anthropologists to the archaeologists, impoverishing social anthropology greatly. It has recently made a partial comeback, for example through the re-examination of Tylor's theories within linguistic anthropology (Gray and Jordan 2000), but remains absent from social anthropology as an explicit subject of study. We therefore have the awkward situation that though obviously the diffusion of ideas, peoples and cultures should be at the heart of our understanding of the emergence of contemporary human society, we can't actually study it as social anthropologists other than through surrogates such as 'globalisation' or 'migration', leaving archaeology or linguistic anthropology to take the study of diffusion forward.

Again, I should clarify my point here. I do not mean to say that Elliot Smith's work should be readopted into our canon in any straightforward way. It was indeed flawed. I do say, however, that he was a more effective man than he has been held up to be, was raising genuinely important issues, and that his dismissal from the academic record should be regarded as a failure rather than a triumph, because it resulted not just in the traducing of a successful and humane albeit difficult man (Brami, forthcoming), but also because this victory turned out to be pyric, it was ultimately to the detriment of the intellectual richness of our discipline.

Through the seminars on the history of anthropology that we have been holding at the institute, it also has gradually become clear to me that the way that the conventional trope puts the Malinowski seminar at the heart of the development of the discipline, is even if not wrong in itself so oversimplified as to be greatly distorting. For instance, we refer to that constellation of anthropology at the LSE at that time informally as the 'Malinowski' seminar, but of course it was not this in any straightforward way - or rather there were two seminars at least, the other ran by Westermarck, Malinowski's teacher at the LSE (Montague 1982).

\section{Westermarck}

If Elliot Smith may be said to have brought down academic obscurity upon his own head, the same cannot be said for Westermarck, whose eclipse is quite unwarranted (Shankland 2014). Westermarck was a Swedishspeaking Finn, who already when he was writing his doctoral thesis decided to create a strong link with British anthropologists (Westermarck 1929). His interventions were crucial to the creation of modern anthropology, above all his insistence that there was no such thing as primitive promiscuity (Westermarck 1891). This meant that the study of kinship could develop without having to assume some hypothetical pre-modern state when marriage did not exist. His linked idea, that the seemingly universal incest prohibition can be explained by the fact that proximity in childhood inhibits mating has been more controversial, but it is yet to be conclusively refuted.

In 1906, he was offered a chair of Sociology at the LSE funded by Martin White, which he occupied until his retirement, sharing the time for much of this period with the University of Abo, where he was rector. Simultaneously, he conducted many years of solo fieldwork in North Africa, and learnt fluent Arabic (Westermarck 1926). In his teaching, he stressed the importance of the analysis of social institutions in ethnographic writing, and spoke eloquently against the use of 'survivals'. He was also a pioneer in the creation of what is now a flourishing sub-division within social anthropology; the anthropology of morals (Westermarck 1906-8). Yet, we do not remember Westermarck, and in the recent celebration to mark the founding and history of anthropology at the LSE, he was not mentioned until there was a question from the audience after the main session was concluded, to the consternation of those who had put it together.

\section{The place of Oxford}

Further, placing Malinowski at the fountainhead of the creation of modern anthropology causes a potential distortion in the way that social anthropology came to be formed. In particular, it leaves out the developments at Oxford, which can be traced in a distinct way, and were equally essential. Evans-Pritchard as Professor of Social Anthropology at All Souls was of course the instigator of the Association of Social Anthropologists of Great Britain and the Commonwealth after the Second World War. The predecessor in his chair was Radcliffe-Brown. 
Radcliffe-Brown had been taught by Haddon and Rivers at Cambridge before embarking on his peripatetic and highly influential teaching career that eventually led him to Oxford. Radcliffe-Brown certainly read Malinowski, but Malinowski was not the prime source for his ideas, which were rather drawn from his Cambridge teachers Haddon and Rivers, from the French sociologists and the idea of a science of society, combined also with his reading of nineteenth century radical socialists (Langham 1981).

In turn, the instigator of the chair at All Souls was Marett, who supported by Myres and Balfour had built on anthropology at Oxford for several decades as gradually the questions that it would address as a modern discipline were being clarified (Riviere 2007). It was Marett, who by making a success of the readership in Social Anthropology that he held was able to secure a successor as he retired, and it was Marett indeed, who diplomatically ensured that it would be called 'Social' Anthropology, a disciplinary orientation that passed through Radcliffe-Brown to Evans-Pritchard.

All this means that far from modern social anthropology having one source, the seminar at the LSE was only one amongst several, and that seminar itself was at least two seminars, rather than a single one. And, in clear contradistinction to the claims of Edmund Leach (1984), who claimed that social anthropology was largely created by outsiders who were not accepted by the 'establishment', we can see that amongst those who were most active were figures entirely successful in English society; Marett was rector of his college, Exeter. Myres was Wyckham Professor, and received a knighthood for his contribution to scholarship. And linking all these centres was the RAI; providing throughout the decades a centre for the discussion, publication and dissemination of anthropology.

In sum then, we may say that though it is absolutely correct to say that those who attended the Malinowski seminar went on to become heads of departments or founding professors in the middle of the twentieth century as the subject began to be founded in university departments, the ideas that they taught and put forward had a much broader social base than they maintained, and the fore-shortened vision of history that they put forward served to create a marker, largely a way of separating them from their contemporaries and the anthropologists who came before them. It was this vision that Adam Kuper wrote down, but it is no more accurate than any other attempt to create a community by developing a shared ideology and putative common past. Whilst it did indeed serve to create an esprit de corps which is still with us today, its excision of its forebears has arguably also had an intellectual cost and creates a lack of historical accuracy. I have given two examples of this: that of Elliot Smith and the study of diffusion, and the foundational, but overlooked role of Westermarck. Further instances could be given, such as Margaret Hasluck's The Unwritten Law in Albania (1964). This is a thoroughly modern text in social anthropology, yet where did it come from, intellectually speaking? The answer is that it appears to have no connection with Malinowski whatsoever - rather its roots can be traced through the University of Aberdeen, the British School at Athens, Frederick Hasluck's work on the Balkans, and the classics tripos at Cambridge under Harrison and Ridgeway at the beginning of the twentieth century (Shankland, forthcoming).

\section{Evolution}

A further, and linked question is how anthropology has dealt with evolution. In any unified vision of anthropology, evolution would and should play a part in framing and elucidating the questions that the subject tackles. For this, one would not necessarily need to embrace the complexities of mathematical modelling, or assume that evolution means 'progress', rather simply to be aware that there are complex series of cause and effect which create patterns rendering one or another configuration more successful than another. Yet (obviously summarising brutally a much wider argument) generations of teachers in social anthropology have regarded the nineteenth century comparative writers pejoratively as 'evolutionist' as if this, in itself were a bad thing. Thereby, there has been created an unnecessary division twice over: the one historical, the other in creating internal disciplinary boundaries as if 'evolutionary' and 'social' anthropologists are doing entirely different things.

Yet, can we really make such a hard and fast division between the earlier and the later writers? Frazer, perhaps the other most common butt of derision after Elliot Smith, is tarred with this brush. But Malinowski - as he himself acknowledged by asking Frazer to write the forward to Argonauts - owed a great deal to Frazer, and Malinowski's model of magic and technology in the Trobriands (Malinowski 1922) is a direct application of Frazer's theories (Frazer 1890). More than this even, the merest cursory reflection shows that broadly speaking Frazer's three-fold conception of historical stages is correct. It may be that we would need to treat the transition 
from magic, or the emergence of religion and science in a much more sophisticated way than did Frazer, but in essence he is not wrong. To dismiss him, therefore, is simply to push the problem away rather than seek to explain it.

At the beginning of this paper, I suggested that one of the reasons that archaeology and anthropology came to divide was the emergence of single-practitioner ethnographic research, which coincided chronologically with the development of multi-practitioner archaeological investigation. Yet, I have gradually become convinced that this too has costs as well as benefits. The freedom that this gives the researcher in social anthropology can be immensely creative, and it produced work that has never been bettered. Yet, as social anthropology has matured and grown the lack of established protocols on what kind of data is collected, and the way that that data is recorded when the researcher is in the field has made it greatly vulnerable because it can appear to become solipsistic, as if the social world outside the investigator has no independent existence.

As there are no agreed parameters as to what constitutes data, it also means that it is difficult to share the kind of expert diverse knowledge of a specific area or site in the way that enriches archaeology so profoundly, and likewise means that social anthropological fieldwork is in danger of falling behind as digitised techniques of data collection become standard in both archaeology and biological anthropology.

There is alas no space here to lay out in detail what I mean. I can give an instance of an exemplary project however - the work designed by Andrea Migliano from UCL, which used digital methods to collect systematic data on dyadic interaction between individuals in hunter-gatherer communities (Salali et al., 2016). In its emphasis on social organisation, the collective base of knowledge, kinship and social interaction it could, and perhaps should, be regarded as an admirable example of contemporary social anthropology, but in terms of its methodology it benefits from techniques which have been developed in biological anthropology, and not in social anthropology.

\section{A holistic anthropology}

What then, is the anthropology that I am advocating should be taught? I would begin by suggesting that all Single Honours courses in anthropology should have a dedicated course in the history of the discipline. It should be holistic in scope, drawing in the period before distinct disciplinary boundaries began to be formed. A possible starting point with regard to the British case would be the nineteenth century, when men and very soon subsequently women began to come together to study how humankind came into being, and how it may differ amongst itself. In this first part, it should also be possible to include the way that anthropology began to take shape in other countries, particularly German, France and Russia. From such a perspective, it would be possible to see clearly that modern anthropology has emerged as a European endeavour as much as a British one, as the work of Vermeulen (2015) helps us to understand.

The famous figures in the nineteenth century could be included easily within such a framework, not as outdated or misguided persons who had no idea what a real native looks like, but rather as highly talented individuals who were curious to find a framework that would be more satisfactory than conventional religious explanations to explain human history, origins, regularity and diversity (Haddon, 1910). The various internal stresses that emerged within the subject as understanding grew can therefore be explored as a reflection of advancement of both our knowledge, and our increasing methodological sophistication. At the same time, the difficulties of maintaining holism can be illustrated through the failure of the RAI to make significant progress on crucial issues, such as race. As distinct sub-disciplines did emerge, however, it would then be possible to trace the way that the components of the holistic intellectual conceptions of the nineteenth century gradually became tied up with particular sub-branches of the subject: in particular deep history, diffusion and chronology with archaeology; social organisation and culture with social anthropology, and the pre-history of human society with biological anthropology.

Within the framework of such a course, it would be possible to illustrate in turn just how the internal boundary markers have come to act as separators of intellectual endeavour, in particular making social anthropology resistant to explore archaeology, when the reverse is not the case. Our explanation of why this is curious asymmetry obtains would be that archaeologists are not dependent in the way social anthropologists became in sketching out their group identity by exclusion of the other. Leaving this admittedly fascinating question to one 
side, surely this holistic approach would be a better way of teaching the history of the discipline that the dismissal by stages which is today so characteristic, but intellectually unsatisfactory.

In closing, it may be legitimate to ask, what sort of linking philosophical framework would obtain this attempt at a holistic endeavour? I do not have the space, sadly, to explore this here, but I would however suggest that it is feasible within the broad parameters of a deductive approach, one that assumes a constructivist perspective. For example, one could reflect on the way a Popperian cosmology would work within such an endeavour: Popper (1950) assumes that the vast bulk of creative speculation is conducted by the investigator before they seek recourse to the external world. In this framework, meaning is provided by the observer and the external world acts only as a check or an ultimate balance to their thoughts. This is certainly not incompatible with social anthropology's conventional emphasis on the social creation of knowledge, and has the added theoretical congruence that Popper himself was fiercely anti-essentialist, and anti-positivist (Popper 1961), just as social anthropology has come to be. Such a deductive perspective too, appears consistent with Evans-Pritchard's envisaging of anthropology as an exploration of historical themes (Evans-Pritchard 1950), and serves as well as any other model to dilute the simple inductivism that Evans-Pritchard thought such a weakness of RadcliffeBrown.

A fuller working out of these thoughts will have to wait until another paper. What effect, however, do I think that the teaching of such a course would have for anthropology? I think, in the first instance, it would be better history than is at present conveyed. To the objection that there is insufficient space in a crowded curriculum, we can say simply that the consequence of having 'no room' for such a course is to give rise to the possibility that generations of students will not have the training to understand the roots of their own discipline. Above all, the aim of such a course would be to be clear about the questions that the discipline has been asking, from whatever sub-field, questions that those who read anthropology can continue to revisit long after their formal education is concluded. There is surely room for this.

Over and above this, however, such an approach would also provide the backdrop for a much greater interaction between the different parts of our subject, an interaction which I think that only properly come about if we remove or at least soften the barriers between them. In doing so, I do not believe that we weaken the strengths or creativity that the establishment of such sub-divisions has given rise to, but we do thereby potentially lessen the disadvantages of the oversimplification that I have touched upon here, and provide a way that in the future we can mutually learn from each other, meaning that our collective discipline will be all the stronger for it.

\section{References}

Banton, M. 2015 What we now know about race and ethnicity, New York: Berghahn Books.

Barkan, E. 1992 The Retreat of Scientific Racism: Changing concepts of race in Britain and the United States between the world wars, Cambridge: CUP.

Brami M.N. (forthcoming), 'The invention of prehistory and the rediscovery of Europe: Exploring the deeper intellectual roots of Gordon Childe's neolithic 'revolution' (1936)'. Journal tba

Congrés international des sciences anthropologiques et ethnologiques: compte-rendu de la premiére session, Londres, 1934. Londres: Institut Royale d'Anthropologie.

Crook, P. 2007 Darwin's coat-tails: essays on Social Damwinism, New York: Peter Lang.

Crook, P. 2012 Grafton Elliot Smith, Egyptology \& the diffusion of culture: a biographical perspective, Brighton: Sussex Academic Press.

Elliot Smith, G. 1934 'Chairman's Address' to Section Aa; Anatomy and Physical Anthropology, in Congrés international; 65-68.

Evans-Pritchard, E. E. 1950 Social Anthropology Past and Present: the Marett Lecture. Man, 50;118-124. 
Frazer, J. 1890 The Golden Bough: a study in comparative religion, London: Macmillan and Co.

Gellner, E. 1995 Anthropology and Politics: Revolutions in the sacred grove, Oxford: Basil Blackwells.

Gingrich, A. 2005 'The German Speaking Countries', in Barth, F. et al One discipline, four ways: British, German, French, and American anthropology, Chicago: Chicago University Press; 61-156.

Glass, B. 1981 'A hidden Chapter of German eugenics beween the Two World Wards', in Proceedings of the American Philosophical Society, 1: 5, 357-36.

Gray, R and Jordan F. 2000 'Language trees support the express-train sequence of Austronesian expansion', Nature, 405; 1052-1055.

Haddon, A. 1910 History of Anthropology, with the help of A. Hingston Quiggin, London: Watts \& Co.

Hasluck, M. 1964 The Unwritten Law in Albania, edited by J. H. Hutton, Cambridge: CUP.

Kuhn, T, 1962 The Structure of Scientific Revolutions, Chicago; Chicago University Press.

Kuper, A. 2015 Anthropology and anthropologists: the British school in the twentieth century, fourth edition. (first edition 1973; revised edition 1983; third edition 1996), London: Routledge.

Langham, I. 1981 The building of British social anthropology: W.H.R. Rivers and his Cambridge disciples in the development of kinship studies, 1898-1931 Dordrecht, Holland: D. Reidel.

Leach, E. 1977 'A view from the bridge', in Spriggs, M. (ed) Archaeology and Anthropology, BAR supplementary series $19,161-176$.

Leach, E. 1984 'Glimpses of the Unmentionable in the History of British Social Anthropology', in Annual Review of Anthropology, 13:

$1-24$.

Malinowski, B. 1922 Argonauts of the Western Pacific, London: RKP.

Myres, J. L. 1931 'International Congress and Institut International: An Interim Report of Recent Negotiations', in Man, 31; 17-20.

Montague, A. 1982 'Edvard Westermarck: recollections of an old Student in Young Age', in Stroup T. Edward Westermarck: Essays on his life and works, Helsinki: Societas Philosophica Fennica, Volume 34: 63-70.

Popper, K. 1950 The Logic of Scientific Discovery, London: George Allen and Unwin.

Popper, K. 1961 The Poverty of Historicism, London: RKP.

Riviere, P. (ed) 2007 A History of Oxford Anthropology, Oxford: Berghahn.

Salali et al., 2016, Knowledge-Sharing Networks in Hunter-Gatherers and the Evolution of Cumulative Culture, Current Biology 26, 2516-2521.

Shankland, D. (ed) 2012 Archaeology and anthropology: past, present and future, ASA Monographs, No. 48. London: Berg. 
Shankland, D. (ed) 2014 Westermarck, Occasional paper No. 44 of the RAI, Canon Pyon, Herefordshire: Sean Kingston Publishing.

Shankland, D. 2016 Review of Kuper (2015) in JRAI: 22. 3: 739-740.

Shankland, D. Forthcoming. 'Margaret Hasluck', in Our Woman in Albania: The Life of Margaret Hasluck, Scholar and Spy, edited by David Oakley-Hill, London: IB Taurus.

Vermeulen, H. 2015 Before Boas: The Genesis of Ethnography and Ethnology in the German Enlightenment, London: University of Nebraska Press.

Weingart, P. 1989 'Science in Germany: The intersection of Institutional and Intellectual Issues', in Osiris, 5: 260282.

Weiss, S. 2006 'Human Genetics and Politics as mutually beneficial resources: the case of the Kaiser Wilhelm Institute for Anthropology, Human Heredity and Eugenics during the third Reich', in Journal of the History of Biology, 39, 1: 41-88.

Westermarck, E. 1891 A History of Human Marriage, London: Macmillan.

Westermarck. E. 1906-8 The Origin and Development of the Moral Ideas, two vols, London; Macmillan.

Westermarck, E. 1926 Ritual and Belief in Morocco, London: Macmillan, two vols.

Westermarck, E. 1929 Memories of my Life, trans. Anna Barwell, London: George Allen and Unwin.

Zollschan, I. [1934] The Significance of the Racial Factor as a basis in Cultural Development, London: Le Playhouse Press.

Zollschan, I. 1943 'How to combat racial philosophy', Man, 68-71; 70. 